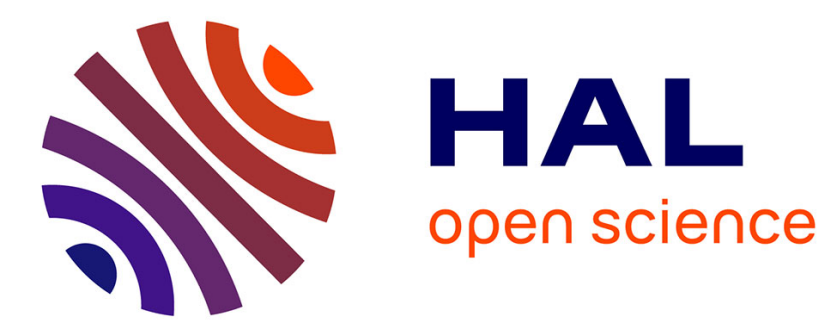

\title{
On the dissociation of hexagonal interstitial frank loops
}

\author{
K. Seshan, R.J. Gaboriaud, M. Boisson, J. Grilhé
}

\section{To cite this version:}

K. Seshan, R.J. Gaboriaud, M. Boisson, J. Grilhé. On the dissociation of hexagonal interstitial frank loops. Journal de Physique, 1976, 37 (12), pp.1493-1496. 10.1051/jphys:0197600370120149300 . jpa00208552

\section{HAL Id: jpa-00208552 https://hal.science/jpa-00208552}

Submitted on 1 Jan 1976

HAL is a multi-disciplinary open access archive for the deposit and dissemination of scientific research documents, whether they are published or not. The documents may come from teaching and research institutions in France or abroad, or from public or private research centers.
L'archive ouverte pluridisciplinaire HAL, est destinée au dépôt et à la diffusion de documents scientifiques de niveau recherche, publiés ou non, émanant des établissements d'enseignement et de recherche français ou étrangers, des laboratoires publics ou privés. 


\title{
ON THE DISSOCIATION OF HEXAGONAL INTERSTITIAL FRANK LOOPS
}

\author{
K. SESHAN (*), R. J. GABORIAUD, M. BOISSON and J. GRILHÉ \\ Laboratoire de Métallurgie Physique, Faculté des Sciences, \\ 40, avenue du recteur Pineau, 86022 Poitiers, France
}

(Reçu le 24 mai 1976, révisé le 5 juillet 1976, accepté le 23 août 1976)

\begin{abstract}
Résumé. - Quelques résultats préliminaires d'un calcul d'énergies d'équilibre des boucles hexagonales de Frank interstitielles sont présentés. Il est montré que les défauts interstitiels pourraient se dissocier suivant des configurations à angle obtus ou aigu. La stabilité de la configuration obtuse dépendrait alors du rapport entre l'énergie de faute intrinsèque et extrinsèque $: \rho=\gamma_{\mathrm{I}} / \gamma_{\mathrm{E}}$. Pour explorer quantitativement cette idée, l'énergie d'équilibre des boucles interstitielles hexagonales a été calculée dans le silicium et il est montré que pour les grandes tailles $(\simeq 2000 \AA)$ une petite différence entre $\gamma_{\mathrm{E}}$ et $\gamma_{\mathrm{I}}\left(\gamma_{\mathrm{I}} / \gamma_{\mathrm{E}} \simeq 0,9\right)$ rend la configuration obtuse plus stable. Il faut alors s'attendre à ce que les grandes boucles hexagonales observées dans les matériaux irradiés présentent une configuration du type obtuse.

Une méthode pour déterminer le rapport $\gamma_{\mathrm{I}} / \gamma_{\mathrm{E}}$ basée sur ces résultats est suggérée.

Abstract. - Some preliminary results of equilibrium energy computations of dissociated interstitial Frank loops are presented. It is argued that interstitial defects could dissociate into acute or obtuse angle configurations.

The stability of the obtuse configuration should then depend on the intrinsic-extrinsic stacking fault energy ratio $\rho$. To quantitatively explore these ideas, the equilibrium energy of hexagonal interstitial loops has been calculated in silicon and it is shown that for large sizes $(\simeq 2000 \AA)$ a small difference between $\gamma_{\mathrm{E}}$ and $\gamma_{\mathrm{I}}\left(\gamma_{\mathrm{I}} / \gamma_{\mathrm{E}} \simeq 0.9\right)$ makes the obtuse configuration more stable. It is therefore likely that the large interstitial hexagonal loops observed in irradiated materials have the obtuseangle configuration.
\end{abstract}

A method for determining the $\gamma_{\mathrm{I}} / \gamma_{\mathrm{E}}$ ratio based on these results is suggested.

1. Introduction. - Loops created by irradiation have been shown to be of interstitial type [1,2]. It is therefore interesting to have some theoretical information about their energetical equilibrium configuration.

This work is particularly concerned with the low stacking fault (S.F.E.) energy crystals $\left(<100 \mathrm{ergs} / \mathrm{cm}^{2}\right)$ where the dislocation dissociation plays an important role in the equilibrium shape of the defect. Recently some experimental works carried out in ion-implanted silicon have shown large interstitial hexagonal Frank loops $[1,3]$. Contrary to the case of hexagonal vacancy Frank loops $[4,5,6,7]$, few theoretical computations concerning the hexagonal interstitial Frank loops have been performed.

In the present work, the different splitting possibilities of the hexagonal loop are considered and their energies computed.

(*) Permanent address : Lawrence Berkeley Laboratory, Hearst Mining Building, Berkeley, U.S.A.
It is shown that different configurations are possible depending on the range of defect size and intrinsic/extrinsic S.F.E. ratio.

2. Hexagonal Frank loop. -2.1 Dissociation ENERGY. - Since interstitial loops have an extrinsic stacking fault, two dissociated dislocation geometries are possible according to the reaction :

$$
a / 3(111) \rightarrow a / 6(112)+a / 6(110) .
$$

The initial Frank dislocation dissociates to give a stair rod dislocation which fixs the hexagonal shape and a shockley dislocation which can glide in the (111) plane leading to an acute or obtuse angle [8] (Fig. 1).

In the most general case four configurations may be imagined. The vacancy loop could dissociate to form the acute configuration (Fig. 1a) where all the fault are intrinsic. It could also dissociate into the obtuse case (Fig. 1b) where the faults in the intersecting (111) plane are extrinsic. 


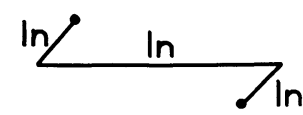

a)

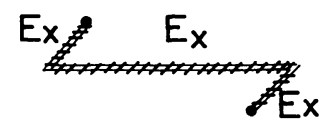

c)

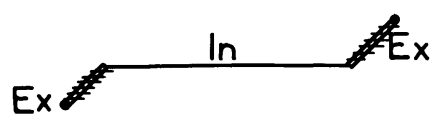

b)

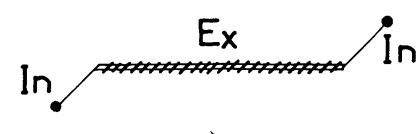

d)

FIG. 1. - The acute and obtuse configuration for vacancy loop (a-b), and interstitial loop (c-d).

The interstitial loop, by the same argument could dissociate into the configuration shown in figure $1 c, d$.

In the acute case the faults are all similar and in the obtuse case the faults are dissimilar.

The configurations in $a$ ) and $d$ ) are likely to form because the fault on the intersecting plane is intrinsic which is more easily nucleated. Furthermore, results from low S.F.E. alloys, as deformed $\mathrm{CuAl}$, alloys show that dislocations spontaneously dissociate to form intrinsic stacking fault [9].

One of the reasons for the difference between the energy of obtuse and acute configuration comes from the interaction energy. Since the Shockley dislocations are attractive, the acute configuration is more likely because these dislocations are close together compared with the obtuse one.

Another reason comes from the possible difference between extrinsic and intrinsic S.F.E.

If $\gamma_{\mathrm{E}}<\gamma_{\mathrm{I}}$ is assumed, as it is shown by calculations in metals [10], the acute configuration would be always favoured.

If $\gamma_{\mathbf{E}}>\gamma_{\mathbf{I}}$ is assumed, as many experimental determinations seem to show $[11,12,13]$ a critical value of the intrinsic/extrinsic S.F.E. ratio : $\rho$, for which the energy of the two configurations will be equal, may be expected.

It seems therefore interesting to compare the equilibrium energies of both configurations taken with the same area, for several sizes and for several values of the ratio $\rho$, in order to determine the influence of those parameters on the equilibrium configuration of the defect.

2.2 ENERGY CALCULATIONS. - The geometrical model taken in this work is the same as that already used for the vacancy hexagonal Frank loop [7].

The energy of the configuration is obtained by approximating the curved dislocations by straight line segments as shown in figure $2 a$.

Details of this kind of calculation, which uses Kroner's continuum theory of dislocations [14] have been given by several authors (see De Witt [15] or $[16,17,18])$.

The energy is the sum of three terms :

$$
E_{\mathrm{T}}(a, h)=E_{\mathrm{S}}+E_{\mathrm{I}}+E_{\mathrm{F}}
$$

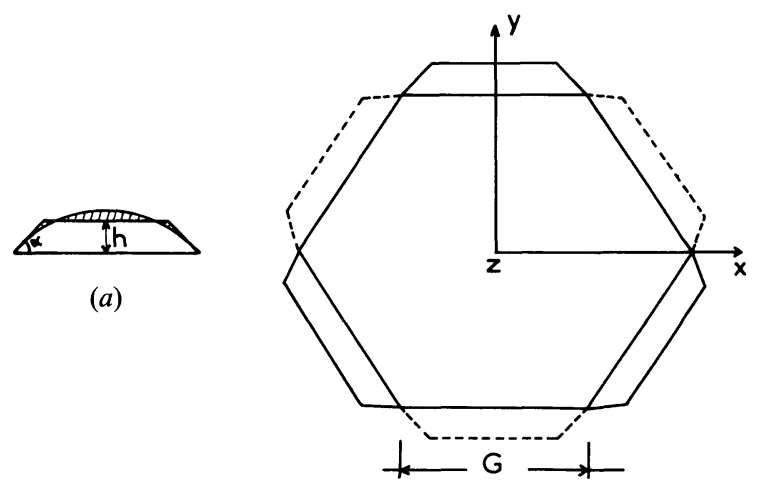

(b)

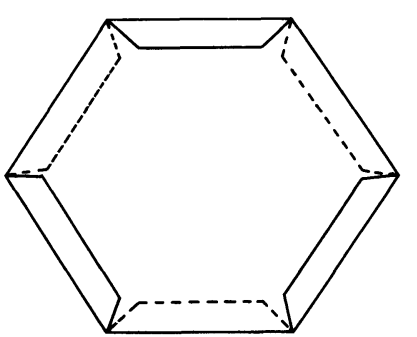

c)

FIG. 2. - a) Approximation and variables of the calculation. b) Geometrical model (interstitial). c) Geometrical model (vancy). - : above the plane; - _ : below the plane.

where $E_{\mathrm{S}}, E_{\mathrm{I}}$ and $E_{\mathrm{F}}$ are respectively the self energy, the interaction energy and the stacking fault energy.

The total interaction energy requires the calculation of 276 interaction energies between straight segments. Using the hexagonal symmetry, this number is reduced to 31 . The equilibrium energy is obtained by minimizing $E_{\mathrm{T}}$ with respect to $(a)$ and $(h)$ which are the two variables of the computation. Two different programs have been used to compute the energies of dissociated and undissociated hexagons. The latter has been found to coincide with the extrapolation of the former to zero dissociation (Fig. 3).

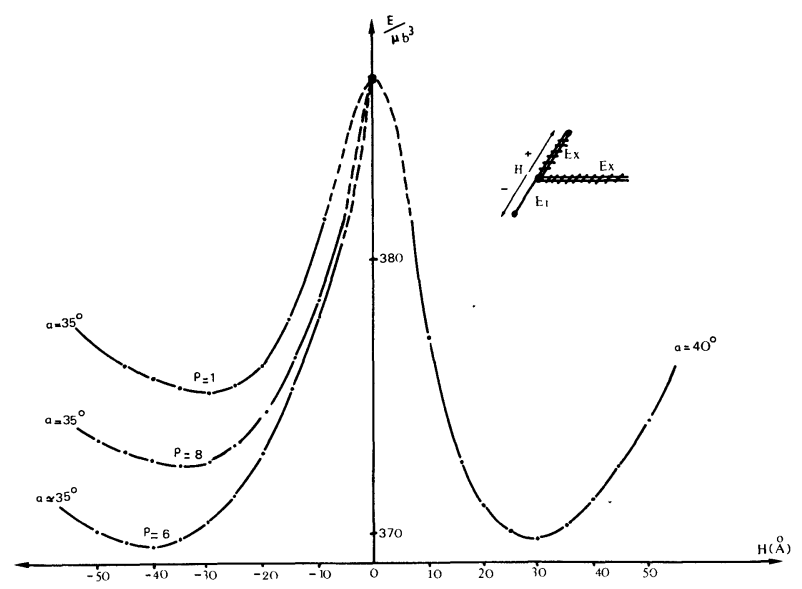

Fig. 3. - Energy variation of the obtuse (left) and acute (right) angle configurations for a length side of $500 \AA$ and for different values of the ratio $\rho: 1,0.8,0.6$. The values of $a$ corresponding to the equilibrium energy are marked on each curve. The constants of silicon used are : $\mu=6.41 \times 10^{10} \mathrm{~Pa}$ (shear modulus); $y=0.215$ (Poisson ratio) ; $\gamma_{\mathrm{ex}}=55 \mathrm{~m}$.joules $/ \mathrm{m}^{2}(17,20) ; a_{0}=5.41 \AA$ Energies are in $\mu \mathrm{b}^{3}$ units $/\left(1 \mu \mathrm{b}^{3}=22 \mathrm{eV}\right)$. 
2.3 RESUlts. - Hexagons with length side of 500, 1000 , and $2000 \AA$ have been considered. The results obtained are illustrated in figure 3 through the example of an hexagonal loop having a length side of $500 \AA$.

The curve on the right corresponds to the acuteangle configuration. The curve on the left corresponds to the obtuse-angle one.

All these curves give the absolute minimum of the energy of the configuration. The minimum energy of the acute configuration is $369.9 \mu \mathrm{b}^{3}$ and corresponds to $a=40^{\circ}$ and $h=30 \AA$.

The minimum energy of the obtuse configuration depends on the ratio $\rho$. The curves on the left of figure 3 show this influence. There is not much difference in the value of $a\left(a=35^{\circ}\right)$ and $h$ increases following the decrease of the intrinsic S.F.E. $(h=30$, $35,40 \AA$ ) when $\rho$ decreases from 1 to 0.6 .

The expected critical value of $\rho$, for which the energies of both the acute and obtuse configurations are equal, appears clearly on these curves. Indeed for $\rho=0.6$. The energy of the obtuse configuration is lower than the acute one. (The critical value is then $\rho=0.61$.)

The same kind of curves are obtained for the other sizes. Side lengths of 1000 and $2000 \AA$ give critical values of $\rho$ which are respectively $\rho=0.78$ and $\rho=0.88$.

From these results, it is possible to define stability zones for each or the two configurations. This is shown on the following plot which gives the side length of the defect $G$ versus the $\rho$ ratio (Fig. 4).

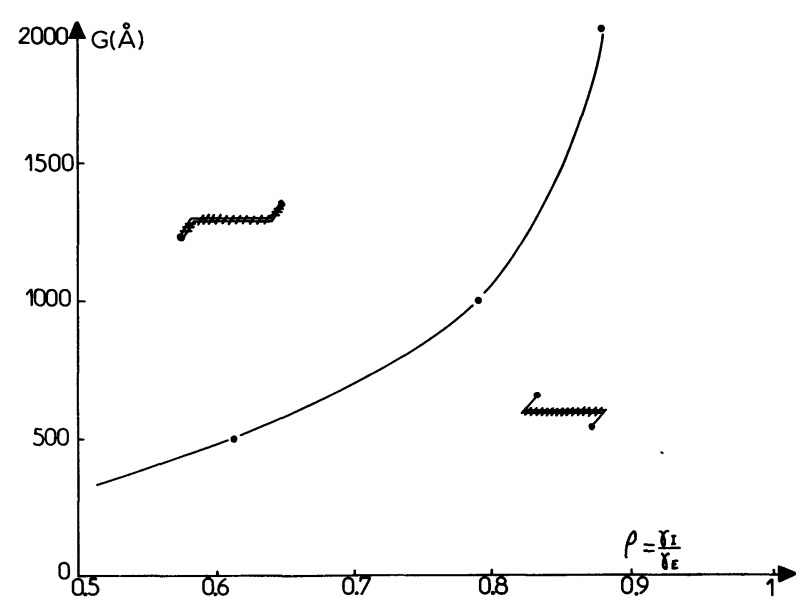

Fig. 4. - Stability zones of the two interstitial hexagonal configurations.

3. Discussion. - One of the results which may be pointed out is the expected energy behaviour of the acute-angle configuration with respect to the obtuseangle one for $\rho=1$.

The general aspect of these calculations is illustrated in the plot showing the stability zones of the two hexagonal configurations (Fig. 4).
On the curve $G=f(\rho)$ the two splitting configurations have the same energy. With $\rho$ near 1., i.e. $\gamma_{\mathrm{E}}$ very close to $\gamma_{\mathrm{I}}$, and with low values of length side. The splitting with acute angle is more favourable. But for large defects $(G \simeq 1000 \AA)$ and with $\gamma_{\mathrm{E}}$ different from $\gamma_{\mathrm{I}}(\rho \simeq 0.8)$. The splitting with obtuse angle is more likely.

On the basis of isotropic elasticity used in this work, insofar as large polygonal defects obtained by irradiation may exhibit obtuse-angle configuration $\left({ }^{1}\right)$, the ratio $\rho$ must be therefore less than 1., i.e. the intrinsic S.F.E. must be lower than the extrinsic one.

The relative importance of $\gamma_{I}$ and $\gamma_{E}$ is subject to controversy and obviously, $\gamma_{I}$ and $\gamma_{E}$ may depend on many physical parameters.

From the curves pictured on figure 3, it seems difficult to imagine a process which could permit the reversion from one configuration to the other.

It would be interesting to study how the initial undissociated defect dissociates in one of the two cases. The explanation is probably in the shape of the curve (Fig. 3) very close to the zero dissociation. This is in dotted line on the graph because it is only an extrapolation. Indeed, elasticity is no longer valid in the immediate vicinity of the dislocation which may be considered as the core dislocation.

Dark field electron microscopy in weak beam imaging conditions might be an interesting way in studying the presence of obtuse or acute-angle configurations. If it is possible to observe both the acute and obtuse-angle configurations, a size measurement would provide an indirect evaluation of the order of magnitude of the intrinsic/extrinsic S.F.E. ratio.

Lastly, such zones of stability should apply to triangular defects as well. This then bears upon the problem of the existence of extrinsic stacking fault tetrahedra [20].

4. Conclusion. - It is argued that hexagonal interstitial Frank loops could dissociate into acute and obtuse-angle configurations.

The results are interpreted in terms of stability zones of the defect defined by the defect size versus the intrinsic/extrinsic S.F.E. ratio.

The relative importance of intrinsic and extrinsic S.F.E. is then discussed. Calculations for silicon show that for large sizes of defect $(\simeq 2000)$, with $\gamma_{\mathrm{I}} / \gamma_{\mathrm{E}} \simeq 0.9$, the obtuse-angle configuration is more likely to occur.

Finally, if electron microscopy using weak beam techniques could confirm the obtuse-angle dissociation, then the ratio $\gamma_{\mathrm{I}} / \gamma_{\mathrm{E}}$ could be estimated by simply estimating the size of the defect.

Acknowledgments. - It is a pleasure to thank Professor J. Washburn for his inspiring interest and for making this collaboration possible.

( $\left.{ }^{1}\right)$ Wilson, D., Private communication. 


\section{References}

[1] Jenkins, M. L., Cockayne, D. H. J. and Whelan, J., J. Micros. 98 (1973) 155

[2] Seshan, K. and Washburn, J., Phys. Stat. Sol. 26 (1974) 345.

[3] Seshan, K., Ph. Thesis, Berkeley (1975).

[4] De Witt, R. and Ruff, A. W., Phil. Mag. 15 (1967) 1065.

[5] BaCon, D. J. and Crocker, A., Phil. Mag. 12 (1965) 195.

[6] BACON, D. J. and Crocker, A., Lattice defects in quenched metals (Academic Press, N. Y.) 1965 p. 667.

[7] Gaboriaud, R. J. and Grilhe, J., Phys. Stat. Sol. 51 (1972) 579.

[8] Seshan, K., Grilhe, J. and Washburn, J., Inter. Confer. on Fund. Aspects of Radiation damage in metals (Gatlinburg, T. N.) 1975.

[9] Hazzledine, P. M., Karnthaler, H. P. and Winter, E., Phil. Mag. 32 (1975) 81.

[10] Blandin, A., Friedel, J., SaAda, G., J. Physique Colloq. 27 (1966) C3-128.
[11] Gallagher, P. C. J., J. Appl. Phys. 37 (1966) 1710.

[12] Hashimoto, H., Howie, A., Whelan, M. J., Proc. Roy. Soc. 269 (1962) 80

[13] Brown, M. L., Phil. Mag. 10 (1964) 441.

[14] KRÖNER, E., Kontinuums theorie der versetzungen und eigenspannungen, ergeb angew, Math., vol. 5 (Springer-Verlag) 1958.

[15] De WITT, Sol. Stat. Phys. 10 (1960) 249.

[16] HiRTH, J. P. and LotHE, J., Mc. Graw Hill, N.Y., 1968, p. 355.

[17] Jossang, T. and Hirth, J. P., Phil. Mag. 13 (1966) 1285.

[18] Humble, P., Segall, R. L. and Head, A. K., Phil. Mag. 15 (1967) 281.

[19] Aerts, E., Delavignette, P., Siems, R., Amelinckx, S., J. Appl. Phys. 33 (1962) 3078.

[20] Gaboriaud, R. J., Seshan, K., Boisson, M. and Grilhe, J., to be published in Scr. Metall. september (1976). 